\title{
Preparation of $\mathrm{FePd} / \mathrm{MgO} / \mathrm{FePd}$ Tri-layer Film on $\mathrm{SrTiO}_{3}(001)$ Single-Crystal Substrate
}

\author{
Shouhei Ouchi, Akira Itabashi, Mitsuru Ohtake, and Masaaki Futamoto \\ Faculty of Science and Engineering, Chuo University, 1-13-27 Kasuga, Bunkyo-ku, Tokyo 112-8551, Japan
}

An $\mathrm{FePd} / \mathrm{MgO} / \mathrm{FePd}$ tri-layer film is prepared on an $\mathrm{SrTiO}_{3}(001)$ single-crystal substrate by employing a two-step method consisting of sputter deposition at $400{ }^{\circ} \mathrm{C}$ followed by annealing at $600{ }^{\circ} \mathrm{C}$. An $L 1_{0}-\mathrm{FePd}(001)$ single-crystal lower layer with the $c$-axis perpendicular to the substrate surface is obtained on the $\mathrm{SrTiO}_{3}$ substrate. An $\mathrm{MgO}(001)$ single-crystal layer is formed on the FePd lower layer. An FePd upper layer epitaxially grows on the $\mathrm{MgO}$ interlayer. The upper layer consists of $L 1_{0}(001)$ crystal involving a small volume of $L 10(100)$ crystal with the $c$ axis parallel to the substrate surface. The order degrees of $L 10(001)$ crystals in the FePd lower and the upper layers are 0.67 and 0.65 , respectively. A very flat surface is realized for the tri-layer film. The tri-layer film shows a perpendicular magnetic anisotropy reflecting the magnetocrystalline anisotropy of $L 1_{0}(001)$ crystal. A formation of fully epitaxial $L 1_{0}-\mathrm{FePd} / \mathrm{MgO} / L 1_{0}-\mathrm{FePd}$ tri-layer film with a perpendicular magnetic anisotropy is demonstrated.

Key words: $\mathrm{FePd} / \mathrm{MgO} / \mathrm{FePd}$ tri-layer film, epitaxial growth, $L 1_{0}$ ordered phase, perpendicular magnetic anisotropy, $\mathrm{SrTiO}_{3}(001)$ substrate

\section{Introduction}

Perpendicularly magnetized thin films with high uniaxial magnetocrystalline anisotropy $\left(K_{\mathrm{u}}\right)$ energies have been investigated for high-density recording media and magnetoresistive random access memory (MRAM) devices. For MRAM device applications, epitaxial (001)-oriented tri-layer films consisting of $\mathrm{MgO}$ and $L 1_{0}$ ordered alloy with high $K_{\mathrm{u}}$ have attracted much attention $^{1-7)}$. The crystal structure of FePt-, CoPt-, or FePd-alloy around the equiatomic composition varies between disordered $(A 1)$ and ordered $(L 10)$ structures. The $L 1_{0}$ ordered alloys have $K_{\mathrm{u}}$ values greater than $10^{7}$ $\mathrm{erg} / \mathrm{cm}^{3}$ along the $c$-axis direction ${ }^{8)}$. Tri-layer films consisting of $\mathrm{MgO}$ and $\mathrm{FePt}^{2-6)}$ or $\mathrm{CoPt}^{4-7}$ ) have been prepared on (001)-oriented single-crystal substrates. An FePd layer has been employed in combination with a very thin $\mathrm{Fe}$ seed layer in the preparation of $\mathrm{FePd} / \mathrm{MgO} / \mathrm{FePt}$ tri-layer on $\mathrm{MgO}(001)$ substrate, and a high order degree is reported ${ }^{9)}$. The ordering temperature varies depending on the magnetic material and FePd-alloy is reported to show higher order degrees compared with those of $\mathrm{FePt}^{-}$and CoPt-alloy thin films ${ }^{10,11)}$. Thus, FePd-alloy is a desirable magnetic material for both the upper and the lower magnetic layers. However, there are very few reports on the preparation of $\mathrm{FePd} / \mathrm{MgO} / \mathrm{FePd}$ tri-layer structure.

The surface flatness, the crystallographic and the magnetic properties are the important issues in the fabrication of practical magnetic devices in addition to the magnetic film order degree. In our previous studies, $L 1_{0}$ ordered $\mathrm{FePd}$ single-layer films with flat surfaces were prepared on $\mathrm{MgO}(001)$ substrates by using a two-step method; low temperature deposition at room temperature ${ }^{12)}$ or $200{ }^{\circ} \mathrm{C}^{13)}$ followed by high temperature annealing at $600{ }^{\circ} \mathrm{C}$. In the present study, an $\mathrm{FePd} / \mathrm{MgO} / \mathrm{FePd}$ tri-layer film is formed on an $\mathrm{SrTiO}_{3}(001)$ single-crystal substrate by employing the two-step method. $\mathrm{SrTiO}_{3}(001)$ substrate is employed for accurate evaluation of $\mathrm{MgO}$ layer by avoiding the overlap of X-ray diffraction (XRD) reflection. When an $\mathrm{MgO}$ substrate is used, it is not easy to extract the crystallographic information of deposited $\mathrm{MgO}$ layer. The initial deposition temperature of $400{ }^{\circ} \mathrm{C}$ in the two-step method is optimized in a pre-experiment to promote the epitaxial growth while keeping a very flat surface structure. In the present study, the film growth process and the film structure are investigated in detail for respective layers in a tri-layer structure with very flat surface. The magnetic properties of a tri-layer structure consisting of epitaxial thin films are also investigated.

\section{Experimental procedure}

Thin films were prepared on $\mathrm{SrTiO}_{3}(001)$ substrates by using a radio-frequency $(\mathrm{RF})$ magnetron sputtering system equipped with a reflection high-energy electron diffraction (RHEED) facility. The base pressures were lower than $4 \times 10^{-7} \mathrm{~Pa}$. Before film formation, $\mathrm{SrTiO}_{3}$ substrates were heated at $600{ }^{\circ} \mathrm{C}$ for $1 \mathrm{~h}$ in the ultra-high vacuum chamber to obtain clean surfaces. Figure 1(a) shows the RHEED pattern observed for an $\mathrm{SrTiO}_{3}$ substrate after heating. A clear diffraction pattern corresponding to a clean $\mathrm{SrTiO}_{3}(001)$ surface is observed, as shown in the schematic diagram of Fig. 1(b). The deposition rates were 0.020 and $0.015 \mathrm{~nm} / \mathrm{s}$ for $\mathrm{Fe}_{50} \mathrm{Pd}_{50}$ (at. \%) and $\mathrm{MgO}$ targets, respectively.

$\mathrm{An} \mathrm{FePd}(40 \mathrm{~nm}) / \mathrm{MgO}(40 \mathrm{~nm}) / \mathrm{FePd}(40 \mathrm{~nm})$ tri-layer film was deposited on an $\mathrm{SrTiO}_{3}$ substrate at $400{ }^{\circ} \mathrm{C}$, and then, the sample was annealed at $600{ }^{\circ} \mathrm{C}$ for $1 \mathrm{~h}$. Although a layer thickness around $1 \mathrm{~nm}$ is generally used for MRAM devices, a thicker layer of $40 \mathrm{~nm}$ was employed in the present study for accurate characterization of epitaxial growth relationship by XRD. In order to characterize the FePd lower and the $\mathrm{MgO}$ layers, $\mathrm{FePd}$ single-layer and $\mathrm{MgO} / \mathrm{FePd}$ bi-layer films were also prepared under conditions similar to the case of $\mathrm{FePd} / \mathrm{MgO} / \mathrm{FePd}$ tri-layer film formation.

The film surface structure during sputter deposition process was studied by RHEED. The film structure was investigated by XRD with $\mathrm{Cu}-\mathrm{K} \alpha$ radiation $(\lambda=0.15418 \mathrm{~nm})$. The surface morphology was observed by atomic force microscopy (AFM). The magnetization curves were measured by using a vibrating sample magnetometer.

The notations of crystallographic plane and direction are different between $A 1$ and $L 1_{0}$ structures. In the present study, the $A 1$-based lattice notation is applied to the $L 1_{0}$ structure for simple comparison with the $A 1$ structure. The long-range order degree $(S)$ value 


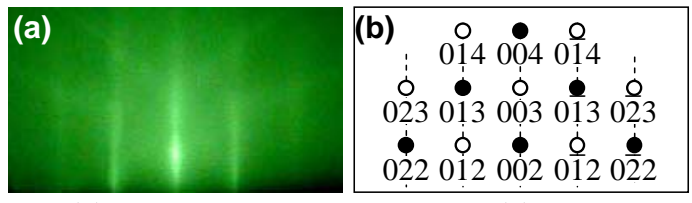

Fig. 1 (a) A RHEED pattern and (b) the schematic diagram of an $\mathrm{SrTiO}_{3}(001)$ substrate after heating. The incident electron beam is parallel to $\mathrm{SrTiO}_{3}$ [100]. The filled and the open circles respectively correspond to the fundamental and the superlattice reflections.
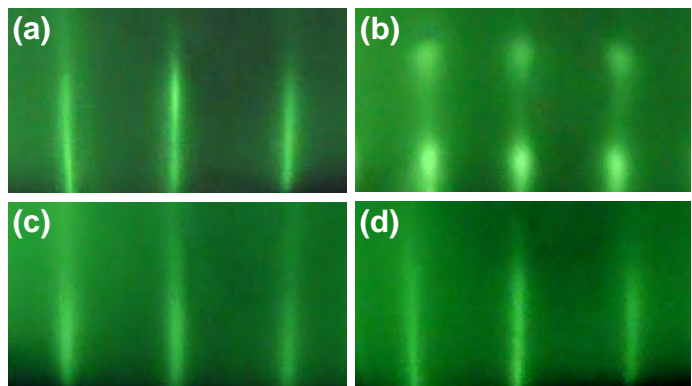

Fig, 2 RHEED patterns observed for (a) the FePd single-layer, (b) the $\mathrm{MgO}$ interlayer, and (c) the $\mathrm{FePd}$ upper layer of an $\mathrm{FePd} / \mathrm{MgO} / \mathrm{FePd}$ tri-layer film deposited on an $\mathrm{SrTiO}_{3}(001)$ substrate at $400{ }^{\circ} \mathrm{C}$ and observed for (d) the FePd upper layer of tri-layer film after annealing at $600{ }^{\circ} \mathrm{C}$. The incident electron beam is parallel to $\mathrm{SrTiO}_{3}[100]$.

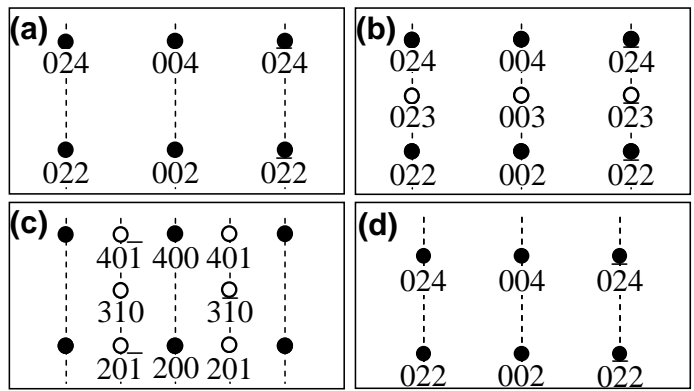

Fig. 3 Schematic diagrams of RHEED patterns simulated for (a) $A 1(001)$, (b) $L 1_{0}(001)$, (c) $L 1_{0}(100)$, and (d) $B 1(001)$ surfaces. The diagrams are calculated by using the lattice constants of (a) $a_{\mathrm{A1}-\mathrm{FePd}}=0.3804 \mathrm{~nm}^{15}$ ), $(\mathrm{b}, \mathrm{c}) a_{\text {L10-FePd }}=0.3850 \mathrm{~nm}, c_{L 10-\mathrm{FePd}}=0.3715 \mathrm{~nm}^{16)}$, and $(\mathrm{d})$ $a_{B 1-\mathrm{MgO}}=0.4212 \mathrm{~nm}^{17)}$. The incident electron beam is parallel to (a) $A 1[100]$, (b) $L 1_{0}[100]$, (c) $L 1_{0}[010]$ and $L 1_{0}[001]$, or (d) $B 1[100]$. The filled and the open circles respectively correspond to the fundamental and the superlattice reflections.

is estimated from the XRD data by using the following relation ${ }^{13,14)}$

$$
S=\sqrt{\frac{I_{\mathrm{s}}}{I_{\mathrm{f}}} \times \frac{\left(f_{\mathrm{Fe}}+f_{\mathrm{Pd}}\right)^{2}}{\left(f_{\mathrm{Fe}}-f_{\mathrm{Pd}}\right)^{2}} \times \frac{(L \times D \times A)_{\mathrm{f}}}{(L \times D \times A)_{\mathrm{s}}}},
$$

where $I$ is the integrated intensity, $f$ is the atomic scattering factor of $\mathrm{Fe}$ or $\mathrm{Pd}, L$ is the Lorentz-polarization factor, $A$ is the absorption factor, $D$ is the temperature factor, and the subscripts of $\mathrm{s}$ and $\mathrm{f}$ respectively refer to $\mathrm{FePd}(001)$ superlattice and $\mathrm{FePd}(002)$ fundamental reflections.

\section{Results and discussion}

Figure 2(a) shows the RHEED pattern observed for

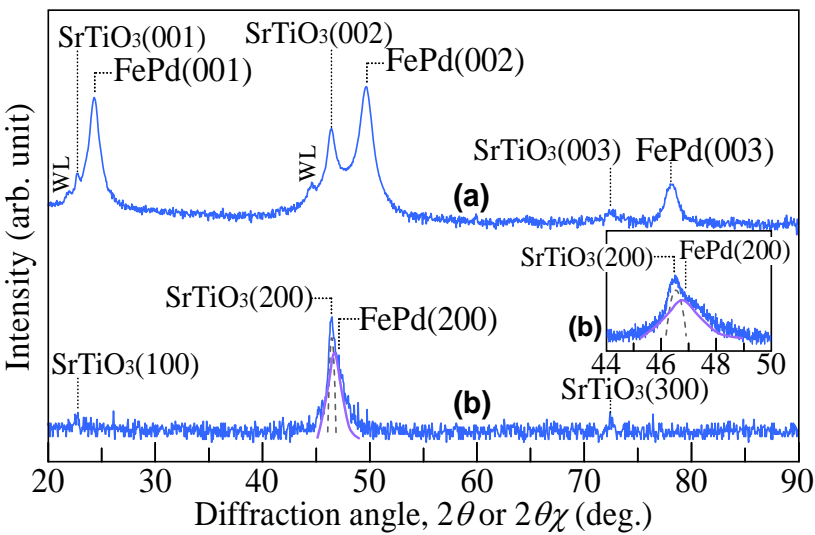

Fig. 4 (a) Out-of-plane and (b) in-plane XRD spectra measured for an $\mathrm{FePd}$ single-layer film prepared by deposition on an $\mathrm{SrTiO}_{3}(001)$ substrate at $400{ }^{\circ} \mathrm{C}$ followed by annealing at $600{ }^{\circ} \mathrm{C}$. The scattering vector of in-plane XRD is parallel to $\mathrm{SrTiO}_{3}$ [100]. The intensity is shown in a logarithmic scale.

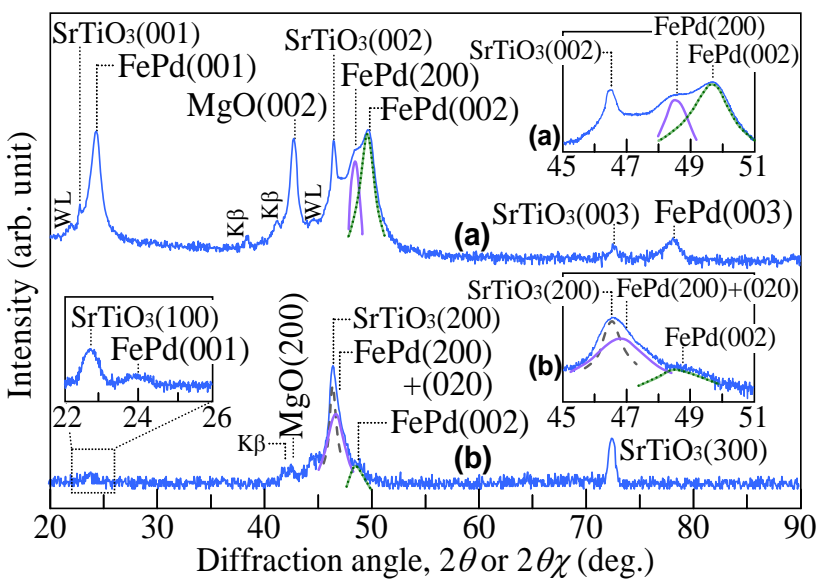

Fig. 5 (a) Out-of-plane and (b) in-plane XRD spectra measured for an $\mathrm{FePd} / \mathrm{MgO} / \mathrm{FePd}$ tri-layer film prepared by deposition on an $\mathrm{SrTiO}_{3}(001)$ substrate at $400{ }^{\circ} \mathrm{C}$ followed by annealing at $600^{\circ} \mathrm{C}$. The scattering vector of in-plane XRD is parallel to $\mathrm{SrTiO}_{3}[100]$. The intensity is shown in a logarithmic scale.

an $\mathrm{FePd}$ layer deposited on an $\mathrm{SrTiO}_{3}(001)$ substrate at $400{ }^{\circ} \mathrm{C}$. A clear diffraction pattern consisting of only streaks is observed. The pattern corresponds to $A 1(001)$ or $L 1_{0}(001)$ single-crystal surface, as shown in the schematic diagrams of Figs. 3(a) or (b). The epitaxial orientation relationships of $A 1^{-}$and $L 1_{0}-\mathrm{FePd}$ crystals with respect to the $\mathrm{SrTiO}_{3}$ substrate are estimated by RHEED as

\section{$\mathrm{FePd}(001)[100]_{A 1} \| \mathrm{SrTiO}_{3}(001)[100]$, \\ $\operatorname{FePd}(001)[100]_{L 10} \| \mathrm{SrTiO}_{3}(001)[100]$.}

When a streak pattern is observed, the identification of crystal structure is difficult, since the A1(001) and the $L 1_{0}(001)$ patterns are very similar. The crystal structure is therefore determined by $\mathrm{XRD}$, which is described later. Figure 2(b) shows the RHEED pattern observed for an $\mathrm{MgO}$ layer deposited on the FePd lower layer at $400{ }^{\circ} \mathrm{C}$. A clear diffraction pattern corresponding to $B 1(001)$ single-crystal surface is recognized, as shown in the schematic diagram of Fig. 3(d). The epitaxial 


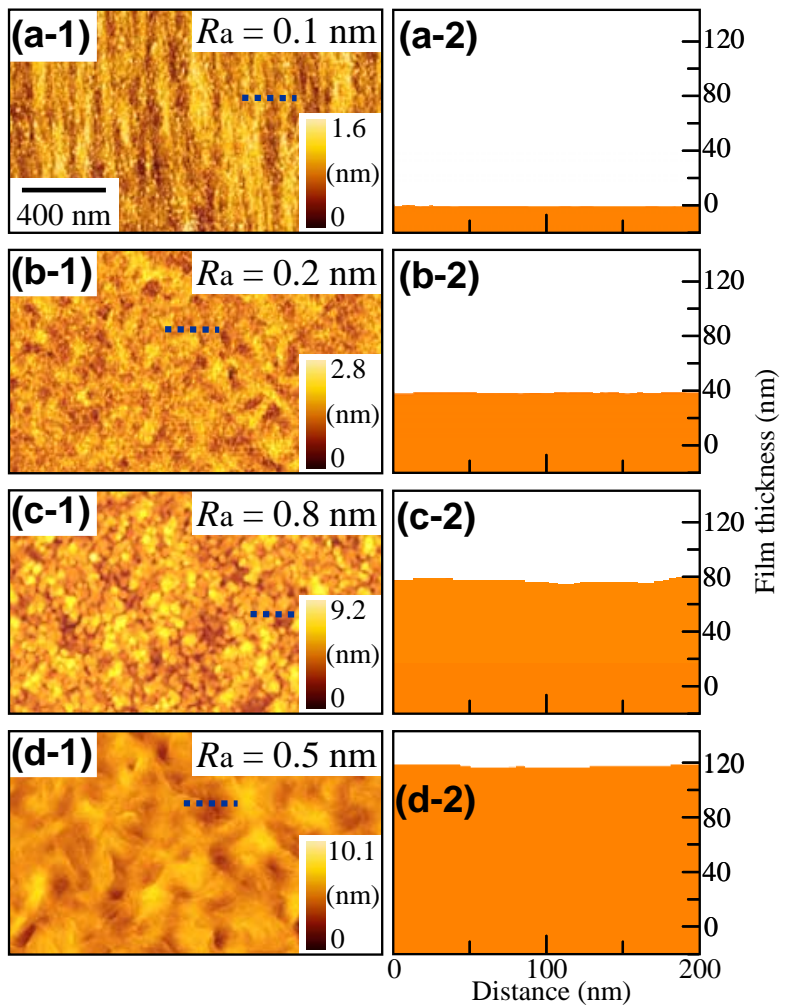

Fig. 6 (a-1)-(d-1) AFM images observed for $(\mathrm{a}-1)$ $\mathrm{SrTiO}_{3}$ substrate and for (b-1) FePd single-layer, (c-1) $\mathrm{MgO} / \mathrm{FePd}$ bi-layer, and (d-1) $\mathrm{FePd} / \mathrm{MgO} / \mathrm{FePd}$ tri-layer films prepared by deposition on $\mathrm{SrTiO}_{3}(001)$ substrates at $400{ }^{\circ} \mathrm{C}$ followed by annealing at $600{ }^{\circ} \mathrm{C}$. (a-2)-(d-2) Cross-sectional profiles measured along the dotted lines in the AFM images of $(\mathrm{a}-1)-(\mathrm{d}-1)$.

\section{orientation relationship of}

\section{$\mathrm{MgO}(001)[100]_{B 1} \| \mathrm{FePd}(001)[100]_{A 1 \text { or } L 10}$} is determined by RHEED. Figure 2(c) shows the RHEED pattern observed for an FePd layer deposited on the $\mathrm{MgO}$ layer at $400{ }^{\circ} \mathrm{C}$. A diffraction pattern corresponding to $A 1(001)$ or $L 1_{0}(001)$ surface is observed, similar to the case of FePd lower layer deposited on an $\mathrm{SrTiO}_{3}$ substrate. The epitaxial orientation relationship is thus

\section{$\operatorname{FePd}(001)[100]_{A 1 \text { or } L 10} \| \mathrm{MgO}(001)[100]_{B 1}$}

Figure 2(d) shows the RHEED pattern observed for the $\mathrm{FePd}$ upper layer of the $\mathrm{FePd} / \mathrm{MgO} / \mathrm{FePd}$ tri-layer film after annealing at $600{ }^{\circ} \mathrm{C}$. The diffraction pattern does not change before and after annealing.

The crystal structure of FePd lower layer in the $\mathrm{FePd} / \mathrm{MgO} / \mathrm{FePd}$ tri-layer structure was evaluated by employing a 40-nm-thick FePd single-layer film prepared by deposition on an $\mathrm{SrTiO}_{3}$ substrate at $400{ }^{\circ} \mathrm{C}$ followed by annealing at $600{ }^{\circ} \mathrm{C}$. Figure 4 shows the out-of-plane and the in-plane XRD spectra measured for the single-layer film. FePd(001) superlattice reflection is recognized in addition to $\mathrm{FePd}(002)$ fundamental reflection in the out-of-plane spectrum, whereas $\mathrm{FePd}(001)$ superlattice reflection is absent in the in-plane spectrum. The result indicates that the $\mathrm{FePd}$ lower layer of the $\mathrm{FePd} / \mathrm{MgO} / \mathrm{FePd}$ tri-layer film does not involve $L 1_{0}(100)$ crystal with the $c$ axis parallel to the substrate surface but consists of $L 1_{0}(001)$ crystal with the $c$ axis perpendicular to the substrate surface.

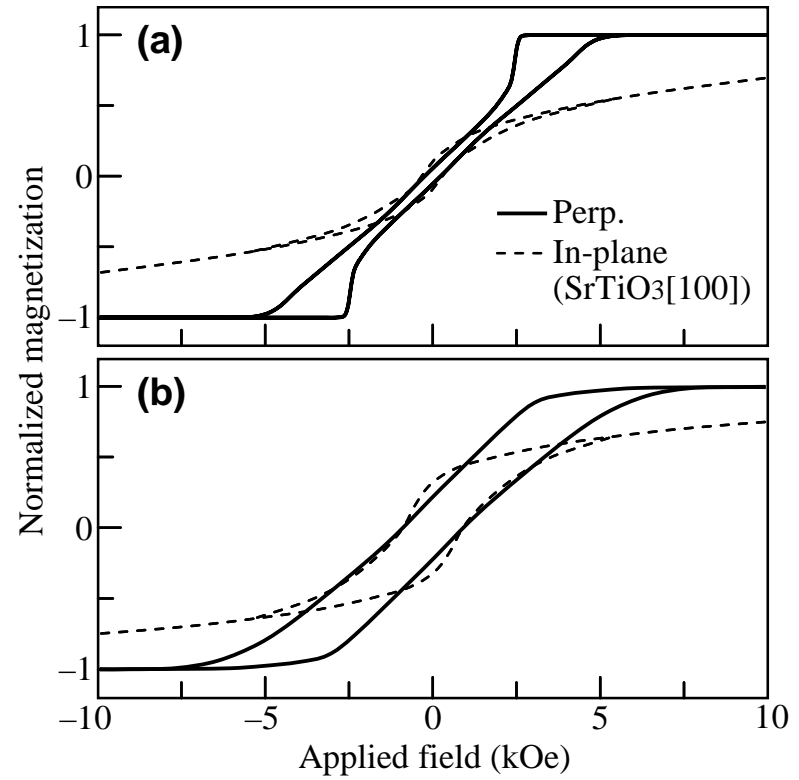

Fig. 7 Magnetization curves of (a) FePd single-layer and (b) $\mathrm{FePd} / \mathrm{MgO} / \mathrm{FePd}$ tri-layer films prepared by deposition on an $\mathrm{SrTiO}_{3}(001)$ substrates at $400{ }^{\circ} \mathrm{C}$ followed by annealing at $600{ }^{\circ} \mathrm{C}$. $\mathrm{SrTiO}_{3}[100]$ is the direction of applied field for in-plane measurement.

The $S$ value is estimated from the out-of-plane XRD data to be 0.67 . A higher $S$ value is expected by further increasing the annealing temperature ${ }^{11,18}$.

Figure 5 shows the XRD spectra measured for the $\mathrm{FePd} / \mathrm{MgO} / \mathrm{FePd}$ tri-layer film after annealing at $600^{\circ} \mathrm{C}$. In the out-of-plane spectrum, $\mathrm{FePd}(200)$ reflection is recognizable in addition to $\mathrm{FePd}(001)$ and $\mathrm{FePd}(002)$ reflections. The in-plane XRD shows $\mathrm{FePd}(001)$ and $\mathrm{FePd}(002)$ reflections in addition to $\mathrm{FePd}(200)$ reflection. These results show that the FePd upper layer consists of a mixture of $L 1_{0}(001)$ and $L 1_{0}(100)$ crystals. The crystallographic orientation relationship of $L 1_{0}(100)$ crystal with respect to the $\mathrm{MgO}(001)$ layer is determined by out-of-plane and in-plane XRD as

$\operatorname{FePd}(100)[001]_{L 10} \| \mathrm{MgO}(001)[100]_{B 1}$. $_{01}$

When the atomic arrangements of $\mathrm{MgO}(001)$ and $L 1_{0}$-FePd(100) surfaces which respectively show four-fold and two-fold symmetries are considered, $L 1_{0}-\mathrm{FePd}(100)$ crystal with the orientation relationship of

\section{$\operatorname{FePd}(100)[010]_{L 10} \| \mathrm{MgO}(001)[100]_{B 1}$}

is apparently formed on the $\mathrm{MgO}(001)$ layer. Thus, the FePd upper layer consists of one $L 1_{0}(001)$ and two $L 1_{0}(100)$ variants. The $c$ axes of two $L 1_{0}(100)$ variants are in-plane and rotated around the film normal by $90^{\circ}$ each other. The $S$ values of $L 1_{0}(001)$ and $L 1_{0}(100)$ crystals included in the $\mathrm{FePd}$ upper layer are respectively calculated from the out-of-plane and the in-plane XRD data to be 0.65 and 0.37. Such difference in the order parameter for $L 1_{0}$ crystals formed in a same film has been reported ${ }^{11}$. The reason is attributed to the difference of distortion along the different orientations in a film which is caused by a mismatch between the substrate and the film. The $S$ of $L 1_{0}(001)$ crystal is twice larger than that of $L 1_{0}(100)$ crystal. Furthermore, the volume ratio of $\mathrm{FePd}(100)$ to $\mathrm{FePd}(001)$ crystal is small, because a clear RHEED reflection corresponding to $\mathrm{FePd}(100)$ crystal formation is not observed as shown in 
Fig. 2(d). The volume ratio of $\mathrm{FePd}(001)_{\text {lower }}$ : $\mathrm{FePd}(001)_{\text {upper }}$ : $\mathrm{FePd}(100)_{\text {upper }}$ is estimated to be 1 : $0.68: 0.32$. Here, the volume ratio of upper layer is estimated from the out-of-plane XRD data assuming that the XRD intensity is proportional to the crystal volume. The overlap of XRD intensity from the lower layer, where only the $L 1_{0}(001)$ crystal is included, is considered in the estimation. Therefore, the $\mathrm{FePd} / \mathrm{MgO} / \mathrm{FePd}$ tri-layer film is considered to show a perpendicular magnetic anisotropy reflecting the magnetocrystalline anisotropy of $L 1_{0}(001)$ crystal.

Figures 6(a-1)-(d-1) show the AFM images observed for $\mathrm{SrTiO}_{3}$ substrate and for $\mathrm{FePd}$ single-layer, $\mathrm{MgO} / \mathrm{FePd}$ bi-layer, and $\mathrm{FePd} / \mathrm{MgO} / \mathrm{FePd}$ tri-layer films prepared by deposition on $\mathrm{SrTiO}_{3}$ substrates at $400{ }^{\circ} \mathrm{C}$ followed by annealing at $600{ }^{\circ} \mathrm{C}$. The delicate differences in the AFM images of Figs. 6(b-1) and (d-1) are possibly reflecting the surface diffusion property of $\mathrm{FePd}$ on $\mathrm{SrTiO}_{3}$ substrate and $\mathrm{MgO}$ layer. Figures $6(\mathrm{a}-2)-(\mathrm{d}-2)$ show the cross-sectional profiles measured along the dotted lines in the AFM images of Figs. $6(\mathrm{a}-1)-(\mathrm{d}-1)$. The surface arithmetical mean roughness $\left(R_{\mathrm{a}}\right)$ values of substrate and respective films are $0.1,0.2$, 0.8 , and $0.5 \mathrm{~nm}$. Flat surfaces are realized for all the cases, which suggests that flat $\mathrm{FePd} / \mathrm{MgO}$ interfaces are realized.

Figures 7(a) and (b) show the magnetization curves measured for $\mathrm{FePd}$ single-layer and $\mathrm{FePd} / \mathrm{MgO} / \mathrm{FePd}$ tri-layer films annealed at $600{ }^{\circ} \mathrm{C}$, respectively. Perpendicular magnetic anisotropies are observed for both films, as expected from the structure analysis by XRD. Similar in-plane magnetization curves are observed when measured along another direction including $\mathrm{SrTiO}_{3}[110]$, which indicates that the in-plane magnetic anisotropy of epitaxial FePd layer is weak. The perpendicular magnetic anisotropy slightly decreases for the tri-layer film when compared with the case of single-layer film. This is possibly due to that the FePd upper layer film involves a small volume of L10(100) crystal. The shape of perpendicular magnetization curve of single-layer film is typical for an $\operatorname{FePd}(001)$ epitaxial film ${ }^{19)}$. On the contrary, the tri-layer film shows the perpendicular magnetization curve (Fig. 7(b)) different from that of single-layer (Fig. $7(\mathrm{a})$ ). This is possibly due to an increase of coercivity of the FePd upper layer.

In the present study, a formation of fully epitaxial $L 1_{0}-\mathrm{FePd} / \mathrm{MgO} / L 1_{0}-\mathrm{FePd}$ tri-layer film is demonstrated by using an $\mathrm{SrTiO}_{3}(001)$ single-crystal substrate. The crystallographic orientation, the surface flatness, and the magnetic property are investigated. These are important properties in designing a tri-layer structure for magnetic device applications. It is necessary to reduce the thicknesses of $\mathrm{FePd}$ and $\mathrm{MgO}$ layers for practical device applications and to further study the influences of layer thickness on the film structure and the magnetic property.

\section{Conclusions}

An $\mathrm{FePd} / \mathrm{MgO} / \mathrm{FePd}$ tri-layer film is prepared on an $\mathrm{SrTiO}_{3}(001)$ substrate by using a two-step method; deposition at $400{ }^{\circ} \mathrm{C}$ followed by annealing at $600{ }^{\circ} \mathrm{C}$. The film growth, the film structure, and the magnetic properties were investigated. The following results are obtained.

1) An $L 10-\mathrm{FePd}(001)$ single-crystal layer with the $c$ axis perpendicular to the substrate surface epitaxially grows on an $\mathrm{SrTiO}_{3}(001)$ substrate. An $\mathrm{MgO}(001)$ single-crystal layer is formed on the $\mathrm{FePd}$ layer. An FePd layer deposited on the $\mathrm{MgO}$ layer consists of $L 1_{0}(001)$ crystal involving a small volume of $L 1_{0}(100)$ crystal with the $c$ axis parallel to the substrate surface. A fully epitaxial $\mathrm{FePd} / \mathrm{MgO} / \mathrm{FePd}$ tri-layer film is obtained on $\mathrm{SrTiO}_{3}$ substrate.

2) The $S$ values of $L 1_{0}(001)$ crystal in FePd lower and upper layers are 0.67 and 0.65 , respectively. The $S$ of $L 10$ (100) crystal in the FePd upper layer is 0.37 . The volume ratio of $\mathrm{FePd}(001)_{\text {lower }}: \mathrm{FePd}(001)_{\text {upper }}$ : $\mathrm{FePd}(100)_{\text {upper }}$ is estimated to be $1: 0.68: 0.32$.

3) The $\mathrm{FePd} / \mathrm{MgO} / \mathrm{FePd}$ tri-layer film prepared by two-step method has a flat surface with the $R_{\mathrm{a}}$ value around $0.5 \mathrm{~nm}$.

4) The $\mathrm{FePd} / \mathrm{MgO} / \mathrm{FePd}$ tri-layer film shows a perpendicular magnetic anisotropy reflecting the magnetocrystalline anisotropy of $L 1_{0}(001)$ crystal.

Acknowledgement A part of this work was supported by MEXT-Japan.

\section{References}

1) Y. Taniguchi, Y. Miura, K. Abe, and M. Shirai: IEEE Trans. Magn., 44, 2585 (2008).

2) M. Hagiuda, S. Mitani, T. Seki, K. Yakushiji, T. Shima, and K. Takanashi: J. Magn. Magn. Mater., 310, 1905 (2007).

3) P. de Person, P. Warin, M. Jamet, C. Beigne, and Y. Samson: Phys. Rev. B, 76, 184402 (2007).

4) N. Inami, H. Naganuma, T. Hiratsuka, G. Kim, T. Miyazaki, K. Sato, T. J. Konno, M. Oogane, and Y. Ando: J. Magn. Soc. Jpn., 34, 293 (2010).

5) N. Inami, G. Kim, T. Hiratsuka, H. Naganuma, M. Oogane, and Y. Ando: J. Phys.: Conf. Ser., 200, 052008 (2010).

6) T. Hiratsuka, G. Kim, Y. Sakuraba, T. Kubota, N. Inami, H Naganuma, M. Oogane, T. Nakamura, K. Takanashi, and Y. Ando: J. Appl. Phys., 107, 09C714 (2010).

7) G. Kim, Y. Sakuraba, M. Oogane, Y. Ando, and T. Miyazaki: Appl. Phys. Lett., 92, 172502 (2008).

8) T. Klemmer, D. Hoydick, H. Okumura, B. Zhang, and W. A. Soffa: Scr. Metall. Mater., 33, 1793 (1995).

9) S. Yoshimura, S. Omiya, G. Egawa, and H. Saito: IEEE Trans. Magn., 47, 4417 (2011).

10) S. Yoshimura, S. Omiya, G. Egawa, H. Saito, and J. Bai: J. Phys.: Conf. Ser., 266, 012114 (2011).

11) M. Ohtake, S. Ouchi, F. Kirino, and M. Futamoto: J. Appl. Phys., 111, 07A708 (2012).

12) A. Itabashi, M. Ohtake, S. Ouchi, F. Kirino, and M. Futamoto: to be published in Eur. Phys. J. B, (2012).

13) A. Itabashi, M. Ohtake, S. Ouchi, F. Kirino, and M. Futamoto: IEEE Trans. Magn., 48, 3203 (2012).

14) B. D. Cullity, in Elements of $X$-Ray Diffraction (Addsion-Wesley, Massachusetts, 1956) pp. 104-137.

15) L. Yiping, G. C. Hadjipanayis, C. M. Sorensen, and K. J. Klabunde: J. Appl. Phys., 75, 5885 (1994).

16) Y. V. Pal'guyev, A. A. Kuranov, P. N. Syutkin, and F. A. Didorenko: Phys. Met. Metallogr., 42, 46 (1976).

17) Z. Feng, V. S. Babu, J. Zhao, and M. S. Seehra: J. Appl. Phys., 70, 6161 (1991).

18) P. Caro, A. Cebollada, F. Briones, and M. F. Toney: J. Cryst. Growth, 187, 426 (1998).

19) D. Ravelosona, A. Cebollada, F. Briones, C. D. -Paniagua, M. A. Hidalgo, and F. Batallan: Phys. Rev. B, 59, 4322 (1999).

Received Oct. 15, 2012; Revised Jan. 21, 2013; Accepted Mar. 1,2013 